\title{
Desesterro: silêncios, construtos e resistências na literatura latino-americana
}

\author{
Desesterro: silences, constructions \\ and resistances in latin-american literature \\ Cláudia Maria Ceneviva Nigro \\ UNESP - São José do Rio Preto \\ Luiz Henrique Moreira Soares \\ UNESP - São José do Rio Preto \\ DOI: https://doi.org/10.5902/2176148537382
}

Resumo: Quando construtos sociais, relativos à mulher na sociedade latino-americana, são questionados, há momentos de resistências. Nesse artigo discorreremos sobre imagens impeditivas de uma resistência de fato, mas propiciadoras de resistência outra no romance brasileiro Desesterro, de Sheyla Smanioto. A fim de comprovar nossa hipótese, temos como fundamentação a instabilidade descrita em condições inviabilizadoras do viver, revelando protestos em desacordo. Não obstante, a "reunião" de mulheres no texto de Smanioto irrompe possibilidades. Para isso, empregaremos a concepção de assembleia de Judith Butler, proporcionando aos leitores uma visada reivindicativa, concedendo eco ao silêncio imposto às vozes femininas presentes no texto.

Palavras-chave: Desesterro. Sheyla Smanioto. Assembleia. Judith Butler.

Abstract: When social constructs concerning women in Latin-American society are questioned, there are moments of resistance. In this article we will discuss on restrictive images of resistance, but propitiating another kind of resistance in the Brazilian novel Desesterro, by Sheyla Smanioto. In order to prove our hypothesis we have instability as foundation described in conditions that prevent us from living, revealing protests in disagreement. Nevertheless, the "gathering" of women in Smanioto's text bursts possibilities. In order to do this, we will employ Judith Butler's conception of assembly providing readers with a target claim, echoing the imposed silence towards women's voices presented in the text.

Key Words: Desesterro. Sheyla Smanioto. Assembly. Judith Butler. 


\section{Cláudia Maria}

Ceneviva

Nigro

Luiz Henrique

Moreira

Soares

68

A literatura latino-americana tem sofrido, nos últimos vinte anos, processos históricos, políticos e sociais que interferem na forma de narrar, ler e escrever, principalmente no concernente à representação de grupos subalternos em um contexto de violências históricas. As mudanças veiculam-se, externa e internamente, na constituição das obras literárias, sobretudo a partir de movimentações em torno da reformulação entre o espaço público e o privado, o conflito entre o urbano e o rural, o estreitamento entre as práticas políticas e os projetos estéticos, a utilização de formas narrativas calcadas pelo hibridismo disciplinar entre o literário e o histórico, além dos deslocamentos de temas e experiências por parte de muitos escritores e escritoras (e também de seus personagens com identidades fraturadas e instáveis), nos obrigando a repensar os critérios hegemônicos de acepção do termo "literatura" e, consequentemente, do conceito de "democracia".

Algumas escritoras, como as argentinas Naty Menstrual (Continuadísimo, 2008) e Susy Shock (Revuelo sur, 2007), alimentadas pelas escrituras de Pedro Lemebel (La esquina es mi corazón, 1995) e Copi (El uruguayo, 1972), ou as escritoras brasileiras Natália Borges Polesso (Amora, 2016), Amara Moira (E se eu fosse puta, 2016) e o escritor Tobias Carvalho (As coisas, 2018), produzem rupturas nas formas de representar as masculinidades e feminilidades, além de propiciar modos não-compulsórios de enxergar os corpos, os desejos e o gênero.

Apesar de ampla e complexa, por abranger um número infindável de obras e autores, as expressões contemporâneas da literatura latino-americana portam-se como espaços possíveis de reivindicação, enunciação e existência para outras subjetividades, não apenas no conteúdo como também na estrutura narrativa, as quais alicerçam problemáticas éticas, estéticas e políticas.

Sheyla Smanioto, escritora brasileira contemporânea, faz parte da safra de escritoras jovens com uma profundidade não circunscrita a "experiências experimentadas", mas a contemplações e elucubrações de vivências outras. Conforme afirma a autora em entrevista ${ }^{1}$ a uma pergunta sobre o tema do romance, mas que cabe para ilustrar a trajetória da escritora/ leitora/ observadora: “eu não conseguiria dedicar tanto tempo a algo que não me comovesse fisicamente. É uma espécie de herança, uma memória ancestral, familiar. Sobrou em mim o instinto, o medo [...]." Diante da resposta, nós, leitores, ficamos muitas vezes sem

1 <http://www.blogdaeditorarecord.com.br/2015/11/16/desesterro-sheyla-smanioto/>. 
ar, no processo de acompanhamento de histórias de mulheres violadas em seus corpos e seus direitos. No entanto, as personagens, sem aparente poder algum, encontram-se posicionadas, cavando o poder nas brenhas da terra nas comunidades fictícias de Vilaboinha e Vila Marta.

Nascida em Diadema, em 1990, Smanioto tem no "poema épico" Dentro e Folha sua primeira publicação no formato de livro cartoneiro, pelo coletivo Dulcinéia Catadora, em 2012. Leitora ávida, conhece Gabriel García Márquez na edição da Folha de São Paulo e se torna uma apaixonada pela literatura latino-americana. Em 2015 publica o primeiro romance, Desesterro, pela Record (prêmio SESC). Outros prêmios se sucedem: Machado de Assis (2016) e terceiro lugar no Jabuti (2016), além de ser finalista do Prêmio São Paulo de Literatura. Em consequência do Prêmio SESC, a escritora apresenta-se no Brasil todo falando e escrevendo literaturas. Assim, nosso enfoque será na obra responsável por divulgá-la no Brasil e no mundo.

\section{O título e a narrativa}

Engendrando a literatura como a arte da palavra, Smanioto inventa o título. Talvez num jogo silencioso entre a terra, a falta dela (des)terra, o desenterrar e o desespero, mas no masculino. A falta de esperança e a violência emplacam na escrita da autora, pois constrói como protagonista do romance Maria de Fátima, sem brecha nem possibilidade no mundo de homens. Um só, o Tonho, é capaz de silenciar, controlar, estuprar, espancar e matar. E basta um! É extremamente valorizado no retrato a ser tirado da família. Contudo, a participação dele não se concretiza. Também não é concretizado o desejo de todas as mulheres que o aguardam: ter uma foto da família. Há sim uma tirada pelo retratista, mas nunca revelada. Para a família feminina desvalorizada só é permitida a espera: a espera do Tonho, a espera do retrato, a espera por ser gente, a espera por não serem devoradas pelo ambiente:

\footnotetext{
O sol penteia lento toda a cena. As sombras trançam. Ele olha com seus três olhos tudo aquela gente. $\mathrm{O}$ sol vai embora, leva o retratista. Nem o vento fica. Só elas, as mulheres. Paradas. Duras. Esperando o Tonho ele já deve estar chegando logo logo, só mais um pouquinho. Elas quietas. Empoeiradas. Plantadas no mesmo lugar (SMANIOTO, 2015, p. 20).
} 


\section{Cláudia Maria \\ Ceneviva \\ Nigro \\ Luiz Henrique \\ Moreira \\ Soares à história da família de mulheres. O narrador onisciente, contador do percurso sem possibilidade de chegada do clã feminino, despe-se de um gênero definido, porém pendendo, muitas vezes, para uma constituição machista claramente instituída, presente nas descrições, falas e com- portamento de todas elas. Gênero e classe social estão imbricados. Não lemos mulheres: apreendemos mulheres pobres, miseráveis com muita frequência, dirigindo-se umas às outras com silêncios e palavras de des- prezo, de privação, de pouquidade. Ouvidas, por séculos a fio, por essas mulheres que as repetem. "- Se sua irmã me ouvisse, veja, parece uma lombriga. Pare de mexer esse tanto, menina, anda, ou não vai caber na fotografia. Olhe o retratista, lazarenta. Não me faz passar vergonha" (SMANIOTO, 2015, p. 14). Só a bebê é elogiada:}

A descrição da cena da espera é poderosa. Em um tempo não marcado, exceto por uma informação sobre a demora da máquina em tirar a foto (15 segundos), o leitor se inquieta e, como no sorriso imóvel pré-foto, a ausência de Tonho torna-se a inexistência de valor dado

\footnotetext{
Coisa mais linda com esse vestido de batismo. Deus que me perdoe ser batizada duas vezes voinha. Não falemos besteira jumenta. Ruim é não ser batizada. E se vira a bênção do avesso, voinha? Pare de ideias tortas, destrambelhada (SMANIOTO, 2015, p. 17).
}

No entanto, ao mesmo tempo, há uma perspectiva de resistência, de voz, em razão de Maria de Fátima propiciar vida para outras três mulheres da família: à avó Penha, lhe fornece sua força física; à irmã menina não nomeada, lhe dá identidade e expectativa de mudança; e à filha Scarlett, lhe permite existir, assim como Cida (mãe) para ela a vida oportunizou. Remexendo o solo da narrativa, desterram-se feminilidades e desenterram-se corpos e memórias silenciadas. O título, portanto, invade o livro ou pode ser também uma narrativa empossada e infestada com o depois do nomear de suas mulheres.

\section{Sororidade ou assembleia?}

O romance Desesterro narra alguns aspectos da vida de cinco mulheres: Maria da Penha, Maria Aparecida (Cida), Maria de Fátima, Maria Menina e Scarlett. Todas elas ligadas por um laço de família e pela pobreza migrante da seca para São Paulo. A ligação dessas mulheres na obra se dá pela sororidade ou, segundo Judith Butler, pela assembleia? 
Por sororidade entendemos aqui a coligação e a convivência entre mulheres. No entanto, esse intenso vínculo acontece fundamentado na compreensão, sintonia e irmandade. Não basta o estar junto realizando um objetivo em comum. No encontro busca-se uma perspectiva de valor ético, retirando-se das mulheres as crenças de inferioridade imputada por juízos sexistas e patriarcais.

Já o conceito de assembleia, para Judith Butler (2015), desvenda a junção de pessoas cujas ações combinam-se aos corpos para performativizar uma ação política nas condições predominantes. A dimensão expressiva da assembleia não se limita às proclamações individuais, mas antes se torna o próprio motivo acoplador dos indivíduos nessa coletividade. Muitas vezes, nem é necessário dizer. O significado das condições precárias do viver alicerça e ampara o protesto explícito e demanda mudanças. 0 corpo expresso e evidente incorpora delineamentos políticos de permanência e resistência.

É claro que uma assembleia exige um número grande de pessoas unidas pela mesma causa e revela o desejo popular. No entanto, trazemos o conceito para nossa análise em consequência de as cinco mulheres de Smanioto figurarem inúmeras mulheres no Brasil em situações vindicadoras de direitos negados.

A escritora dispõe visibilidades nos corpos de suas mulheres, expondo ao mesmo tempo vulnerabilidades e movimentos primevos de associação para, de certa forma, "introduzir" mulheres cujas práticas, forçosamente patriarcalizadas, desmontam nossos conceitos de feminismo, decretando uma outra feminilidade da qual a solidariedade é imprescindível.

\section{Maria da Penha}

O primeiro capítulo, "Três Olhos", inicia-se com a apresentação das personagens na imagem do retrato aguardado. A avó reúne as duas netas (Maria de Fátima e a Menina) na tentativa de recriar o batizado da bisneta (Scarlett). No entanto, quem o narrador segue é o retratista. $O$ definir do ângulo para a foto passa pela paisagem, pela história e evidencia a situação das mulheres no interior seco do Brasil. A foto constitui-se assim denúncia, institucionalizando a esperança - ter amor familiar em uma situação adversa ao amor.

Penha resguarda outras mulheres, no texto animalizadas, intercedendo pelas fêmeas da "favela" de Vilaboinha. Até mesmo o único cão sobrevivente é uma cadela: magra, forte, quieta, existindo ali como um corpo reivindicatório. Bem como Maria de Fátima, a Menina e Scarlet. A avó elabora-se forte para que as outras sobrevivam. 


\section{Cláudia Maria}

Ceneviva

Nigro

Luiz Henrique

Moreira

Soares

Não é à toa que em Vilaboinha só a Penha tem cachorro. Ele late quieto, levanta com a terra, só uiva dentro do vento. Penha sabe do que Vilaboinha é capaz, por isso ensinou as netas a levarem a vida quietinhas, quietinhas, dentro do silêncio, escondidas. Disfarça Maria de Fátima, baixa esses olhos, menina. Não inventa ou vai acabar espantando a vida. Por isso ensinou as netas. Elas não tem que passar pelo que passou por ela (SMANIOTO, 2015, p. 10).

Penha também reproduz muitas vezes o discurso machista por subsistência, ordenando e desmerecendo as netas. Para enganar a fome, trabalha muito. A escassez é reproduzida na personagem: "com a barriga ancorada na pia, a vó Penha vivia arrastando colher no fundo do caneco para não restar nem dúvida nem grão de açúcar" (SMANIOTO, 2015, p. 12); “[...] Penha toma o caneco do chão, sacudindo a cabeça para os pensamentos desgrudarem do fundo. Os grãos de açúcar, tinhosos, aí é que resolvem cair" (SMANIOTO, 2015, p. 13). Esse comportamento da avó da comunidade familiar conecta-se a inúmeras "fêmeas" líderes famintas da seca, comprovando, como afirma Butler (2015, p. 1-2), “[...] governadas por medos do caos ou por uma esperança radical de futuro, embora, algumas vezes, o medo e a esperança são interligados em momentos complexos". E que complexidades apresenta Penha:

A senhora mais velha sorri. Os pés plantas carnívoras no chão. Bocas descalças. Os dentes dedos à mostra. $\mathrm{O}$ vestido branco, $\mathrm{a}$ renda gasta. Os olhos segurando o mundo pelas alças. E ela sorri. Contra tudo ela sorri. Não parece satisfeita, os peitos secos, os cabelos em maço. Quer um dia perdido, o batizado. Quer um tempo partido, um reencontro, uma volta. Mas sorri, sim, sorri. Sorri contra todos os calos. Sorri, sim, sorri, sorri, sorri. Ela sorri para mostrar os dentes (SMANIOTO, 2015, p. 21).

Almeja sorrir e o sorriso faz-se denúncia da miséria e dos maus tratos. A escritora usa a iterabilidade derridiana ao repetir o verbo sorrir. Um sorrir saído para o retrato, sem controle, um sorriso nervoso perdendo a alegria a esse vocábulo associado. Um sorriso expositor de memórias, de histórias, cujos finais almeja alterar. Uma delas é a da filha. 


\section{Maria Aparecida (Cida)}

Esta personagem manifesta-se pouco, pois desde o início da narrativa só vem pelas lembranças da Penha. “A Penha para ter cria jurou, fez promessa, por isso quando nasceu a Cida ela botou foi logo o nome de santa" (SMANIOTO, 2015, p. 47). Cida tem duas filhas, Maria de Fátima, proveniente de "bucho grande em terra farta" (SMANIOTO, 2015, p. 54), e a Menina, vinda do nada, da sem barriga da mãe. Cida morre no parto, feito só e em casa. A mãe a encontra: "porque eu encontrei a menina no meio das tripas de sua mãe" (SMANIOTO, 2015, p. 55) e tudo escurece.

Antes de morrer é Cida a mensageira das mulheres em assembleia. Faz a comunicação familiar. Recebe visitas do outro mundo.

A Cida sempre tinha recado de família. Quando era pequena, pequeninha, ela sonhava com a avó a bisavó a tataravó três carrancas emburradas, mostrando os dentes para a vida. [...] vivia sonhando com domingos. Mas entendia o sonho de toda gente, com terra, com morte, com cabrito [...] toda gente dizia chama a Cida [...] chama a Cida, de sonho a Cida conhece. Bem dizer a Cida quando era viva tinha essa mania: encontrar verdade por trás de tudo nos sonhos, nos dela e nos de toda gente (SMANIOTO, 2015, p. 57-58).

Nela, isso é associado ao bem, pois obedece outras mulheres, vivas e mortas da família. Um dia pedem para cavar em redor da casa em busca de relíquias e ao nada encontrar sai amaldiçoando o mulherio. $\mathrm{Na}$ estrada encontra um estrangeiro: "o sujeito tento dizer para a Cida [...] A Cida [...] não entendia nada. Era uma reza, só podia ser, o sujeito punha os dentes no caminho, Cida não entendia nadinha, o sujeito trotava com os dentes, vê se pode, ciscava a língua. Foi ciscar na nuca de Cida nos beiços nos peitos. O pai de Fátima" (SMANIOTO, 2015, p. 65).

Cida, que carrega o passado e o futuro em revelações oníricas, faz parte da assembleia de Vilaboinha: de mulheres solicitando chamegos, mas sem oportunidade de escolhas. Butler atesta ser:

[...] esse corpo e esses corpos que requerem emprego, abrigo, assistência médica e alimentação, bem como um senso de futuro sem ser o futuro do débito impagável; é este corpo, ou esses 
corpos, ou corpos como esses corpos, que vivem a condição de um meio de vida em perigo, a infraestrutura dizimada, a precariedade acelerada $(2015$, p. 10$)$.

\section{Cláudia Maria}

Ceneviva

Nigro

Luiz Henrique

Moreira

Soares

E por isso estão unidos em assembleia, expressando a precariedade.

\section{Maria de Fátima}

Maria de Fátima é a pretensa protagonista dessa história de mulheres. Congrega, como a mãe, vários papéis: de neta ajudante, de mãe da bebê Scarlett, de irmã/mãe da menina, além de enfrentar o machismo agora com nome: Tonho. $\mathrm{O}$ sonho de Cida traz a morte para a mãe e para a filha. Fátima é um corpo abjeto. Passa pela não vida culpabilizada por imposição da sociedade patriarcal: a de ter desejos e querer prazer. Mas seu corpo é maltratado e brutalizado pela fome e pela falta.

\footnotetext{
-- Sua mãe está morta? E você está o quê, viva? Fátima faz que não ouve.

-- Tem tanto jeito de morrer como tem jeito de viver, Fátima. Ninguém nem sabe que está morto até ver que vivo é que não estava. Às vezes a morte vem de barriga grande, anunciada, outras vezes ela só já veio, é bom que saiba (SMANIOTO, 2015, p. 56).
}

Vítima de abuso intenso, Fátima, para a irmã e a filha, é modelo a não ser seguido. 0 descrever da personagem é paradoxal. Temos personagens mulheres sobreviventes, mas um narrador seguindo o ponto de vista machista, pedófilo e violento de Tonho para descrever os abusos de um modo "natural", como se esse tratamento fosse amor. "Pegou Fátima para casar ela ainda era pequena quase uma criança. Não gostava nem dela diacho, nem gostava dela menina" (SMANIOTO, 2015, p. 83).

A personagem tem, como as outras, uma relação com a terra como masculina, devorando sonhos e cavando os corpos. Essa relação é de amor e ódio, construção e destruição. É assim com as avós mortas, com Cida, com Penha e com as netas: homens cavando a terra (próximo às casas, na favela de Vila Marta) e encontrando o corpo de Maria de Fátima em Vilaboinha.

Vilaboinha parece, pela descrição do ambiente, encontrar-se no roteiro da seca e da fome. Não há menção a um estado, mas à pungência da terra improdutiva, da intensa violência de gênero e da falta (até de cachorros). Já Vila Marta está em São Paulo, naquela cidade brasileira 
representada como o local das oportunidades. O sonho da migração. No entanto, a realidade da busca prova-se ficção: Vila Marta transborda escassez. E a Maria de Fátima presente em São Paulo é a outra.

\section{Menina, sem nome, Menina Maria}

A Menina sem nome é a "responsável" pela morte da Cida, no parto. E, se a Cida não a nomeou, não deve ser nomeada, de acordo com Penha. A personagem divide o protagonismo com Fátima quando "rouba" a identidade da irmã morta e foge para São Paulo. A Maria de Fátima da Vila Marta é a menina. Descrita desde sempre como incômodo, por meio dela

[...] o problema da demarcação [de quem pode ser considerado pessoa] introduz outra dimensão para o problema, uma vez que nem todas as ações discursivas relacionadas ao reconhecimento e ao desconhecimento das pessoas são explícitas. A operação do poder deles é, em certa medida, performativa. Ou seja, promulgam certas distinções políticas, incluindo desigualdade e exclusão, sem nomeá-las (BUTLER, 2015, p. 6).

Como o "elo fraco" entre as mulheres, Menina tem a existência mais consciente. Faz parte dos corpos femininos reunidos em Vilaboinha como aquela que tudo vê e, por isso, desgosta a avó e Maria de Fátima. É como se ela estivesse ali desvendando o silêncio. Sua própria existência é prova do estupro de Fátima. É filha de Tonho e Cida. Aquela indesejada, pois revela ser o óbito da mãe resultado da tristeza de perceber o pai assediando a própria filha. No entanto, por ela, o desejo de liberdade das outras é realizado. Menina foge para São Paulo, vive 20 anos livre. Quando a avó Penha morre, recebe Scarlett como filha. Realiza o sonho da irmã. "Fátima tem para ela que São Paulo é terra boa de chegar. Fátima e a criança vão chegar na chuva, vão tomar banho de chuva no banho de chuva nada fica, só a gente. A terra vai toda embora vão junto as lembranças de Vilaboinha" (SMANIOTO, 2015, p. 90). Menina é a responsável por salvar Scarlett: "Tonho nunca viu a menina ou a criança. [...] a menina pegava Scarlett e as duas ficavam embaixo da pia" (SMANIOTO, 2015, p.183).

Menina/Maria de Fátima também é mulher de desejos. Aprendeu a desejar e fugir dos desejos. Enxerga demais. E por descortinar a situação da mulher, menina carrega Cida, Fátima e Scarlett consigo na fuga. Não deixa o sonho de Fátima morrer com ela nas mãos de Tonho. 


\section{Scarlett}

A netinha linda de Penha, sobrevivente de Vilaboinha como a cadela magrela, é rara. A única da família saindo de Vilaboinha sem se esconder de ninguém, a única a irromper o percurso cultural dos nomes de santas,

Cláudia Maria

Ceneviva

Nigro

Luiz Henrique

Moreira

Soares

76 a única com nome de artista internacional. Aquela que escapa do estupro do pai. Scarlett já nasce forte, num parto sem recurso, nem parteira. Como os bebês da vila/favela fazem a jornada do nascer por si mesmos:

Só nasce mesmo a criança que vai tateando até a beira, não cansa, o miúdo que vai tateando, tateando e até que alcança, na carne, a vida esse buraco imenso. As outras ficam perdidas, o cordão umbilical pelo pescoço, uma preguiça de sair da barriga, dormindo dentro mais um pouco (SMANIOTO, 2015, p. 45).

O trajeto sofrido mostra-se comparado a vida das mulheres, tateadoras, perdidas e desvinculadas a propósito do viver, como artifício e engenho do permanecer. Scarlett é o resultado do estupro, das pancadas recebidas, da ausência. E ainda assim, faz-se mulher e muda-se para São Paulo atrás da mãe. Quem a recebe é a irmã "vestida" de mãe: “Tonho nem ligava pras filhas, nem para Scarlett, muito menos para a menina [...] ele nem devia saber que Scarlett veio para São Paulo sozinha de mala e cuia" (SMANIOTO, 2015, p. 185). E quem a manda de volta aos espíritos da família é a irmã/tia, resolvendo a violência recebida de Fátima e nela impetrada. Na chegada de Tonho à Vila Marta vinte anos depois, morre o Tonho destroçado pelos cães e morre Scarlett espancada pelas memórias de violência da menina sempre exposta a atrocidades e à barbárie. Assim, da assembleia sai uma voz: a voz da menina que devora Marias, a que destrói culturas estabelecidas por regras não feitas por mulheres.

\section{Tonho}

Tonho é o predador. A personagem escancara o patriarcalismo, expondo o machismo como doentio. Tonho é violento ao mesmo tempo em que tem um medo insano de cães. Ele bate e mata o não entendido, como cães e mulheres. "Tonho tantas vezes batendo em Fátima ela nem se importa, nenhuma mulher morreu de apanhar do marido, exceto as que estão mortas" (SMANIOTO, 2015, p. 106). Na assembleia Tonho é considerado não-humano. Butler (2015, p. 4) afirma que as assembleias se autonomeiam e definem os que são incluídos e os que não são. Tonho certamente 
não é. Parceiro de Cida, afirma ficar com a mãe ao mesmo tempo em que teve interesse na filha. A cena de estupro de Fátima menina é descrita comparando-a com a cadela. Porém, novamente, o narrador diz a partir do ponto de vista de Tonho, minimizando o sofrimento de Fátima. 0 narrador mostra anteriormente uma sexualidade na menina, como se o estupro pudesse ser justificado. Ora leitor, toda mulher tem desejo, nem por isso quer aquilo que se apresenta. Não é obrigada a querer:

Ela começou a se debater feito cadela, e eu queria mais ainda, diacho, quando mais ela se debatia, a cadela, mais fundo eu ia nela [...] Começou a chorar, a desgraçada, como se eu tivesse fazendo Desesterro mal pra ela [...] Chutei a cadela. Sossega, eu martelei bem fundo nela, para de fingir que não gosta, eu sentia nas pernas putas dela que é disso que ela gosta, sentia nas mãos a cara rapariga dela, e ela resolvia mudar de ideia? Jogo de mulher quer não quer, diacho, igualzinho à mãe dela (SMANIOTO, 2015, p. 112).

Smanioto, em entrevista, afirma que é "Do teatro... que você consegue impor uma respiração para o seu público". No nosso entender, essa cena tira completamente a respiração do leitor. Dá dor de estômago, dá vontade de vomitar na cara dos tonhos/machos estupradores de mães e filhas.

\footnotetext{
[...] Eu falei pra ela que a mãe dela ia ficar era brava com ela se descobrisse a putinha que ela é [...] Foi quando bateram na porta para avisar que morreu a Cida. [...] Com a mãe de Fátima morta, ela não era mais minha filha. Fiquei doido só de pensar em outro homem indo lá devorando minha cadelinha, e de pensar nela se debatendo em vara que não é nem minha (SMANIOTO, 2015, p. 113).
}

Tonho simboliza o dejeto a ser dispensado e evitado. Com a criação da personagem, Smanioto faz um desserviço, em razão de servir-se de um narrador que reforça o machismo institucional existente. E não é só Tonho o responsável por isso. Em relação à menina, Penha e Fátima agem cruelmente tentando impor uma imagem de mulher submissa à menina, uma imagem de mulher sem ação diante da metanarrativa da impossibilidade. A “menina jagunço” é destratada, desmerecida, espancada, amaldiçoada. 
Apesar disso, ao mesmo tempo, Smanioto oportuniza conhecimento a repeito do sexismo, pois, embora afirme ser a arte a prática da reflexão sobre a realidade, evidencia, exterioriza e elucida a vida de abjetos na sociedade brasileira. Individualmente, as mulheres de Sma-

Cláudia Maria

Ceneviva

Nigro

Luiz Henrique

Moreira

Soares nioto não têm voz, mas nas ruas das favelas, de norte a sul, democraticamente em assembleia, denunciam um Brasil e uma America Latina misógina e patriarcal. Com certeza, o romance surpreende o leitor.

BUTLER, Judith. Notes Toward a Performative Theory of Assembly. Massachusetts: Harvard University Press, 2015.

RODRIGUES, Henrique. Entrevistas: Desesterro, de Sheyla Smanioto. Disponível em: <http://www.blogdaeditorarecord.com.br/2015/11/16/ desesterro-sheyla-smanioto/>. Acesso em: Janeiro de 2019.

SMANIOTO, Sheila. Desesterro. Rio de Janeiro: Record, 2015. 